\title{
Underground Magnetic Dipole Representing a Seismomagnetic Effect
}

\author{
Naoto OHSHIMAN \\ Department of Applied Physics, Tokyo Institute of Technology, \\ Tokyo, Japan
}

(Received August 15, 1979; Revised March 6, 1981)

\begin{abstract}
Surveys of the geomagnetic total intensity have repeatedly been carried out in the western part of Izu Peninsula about $100 \mathrm{~km}$ southwest of Tokyo. One of the most remarkable changes in the total intensity seems to be associated with the Izu-Oshima Kinkai earthquake of magnitude 7.0 that occurred on January 14, 1978.

The origin of the observed changes was investigated using a method to find an underground magnetic dipole corresponding to geomagnetic changes observed on the earth's surface. The result suggests that the origin of changes in total intensity during preand post-earthquake periods would be an increase of tectonic stress. On the other hand, the origin of changes associated with the earthquake occurrence is not likely to be directly associated with aftershock activity in the western part of Izu Peninsula but rather likely to have something to do with an effect of the main shock.
\end{abstract}

\section{Introduction}

STACEY (1964), YUKUTAKE and TACHINAKA (1967) and others presented a few models by which we may account for seismomagnetic effect. The pattern of anomalous magnetic field arising from such models seems likely to be expressed, to a rough degree of approximation, by that of a hypothetical dipole assumed under the ground surface. This also the case of an actually observed anomalous change in the geomagnetic field as revealed by comparing a pre-earthquake magnetic survey to the post-earthquake one.

RIKITAKE (1950a, b) proposed a method of finding the position, intensity and direction of an undergound magnetic dipole which approximately accounts for a magnetic anomaly observed on the earth's surface. This method was applied to the changes in magnetic dip observed in association with the Shizuoka earthquake of July 11, 1935, and the 1950 eruption of Volcano Mihara, (RIKITAKE, 1951). These dipoles representing magnetic anomalies are supposed to be given rise to by demagnetization of rock constituting the volcano due to the increase in temperature in the case of the eruption of Volcano Mihara and by the effect of stress on remanent magnetization of rocks (NAGATA, 1969) in the case of the Shizuoka earthquake. It now appears that piezomagnetic effect is important even for a volcanic case (e.g., DAvis, 1976; SASAI, 1979). It was also reported by Fujita (1965) that the changes in the declination, horizontal intensity and vertical intensity observed in association with the 1964 Niigata earthquake were well approxi- 


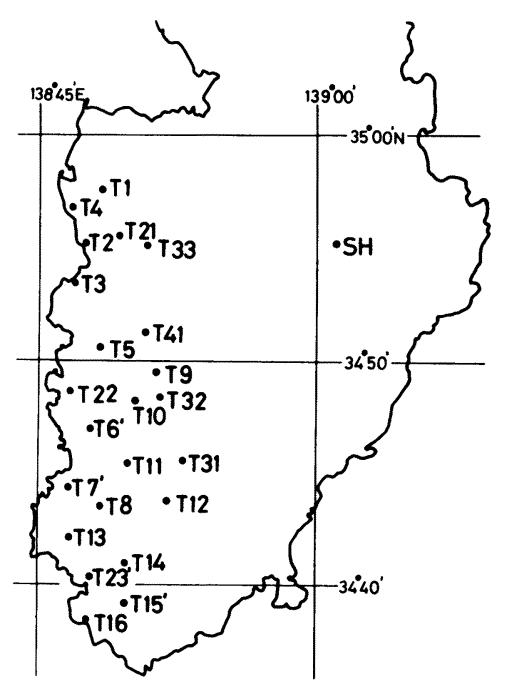

Fig. 1. The distribution of magnetic station for magnetic total intensity in the western part of Izu Peninsula. SH: Sugehiki station by Earthquake Research Institute.

mated by an underground magnetic dipole.

The magnetic surveys have repeatedly been carried out in the western part of Izu Peninsula since 1976 (TANAKA and OHShiman, 1978). In 1978, the surveys were carried out in January immediately after the occurrence of the earthquake and also in March, about two months later. Figure 1 illustrates the distribution of magnetic stations in the western part of Izu Peninsula. The stations indicated by numbers with a prime symbol were reestablished because of artificial disturbances. Figure 2 illustrates the total intensity changes at respective stations relative to the Kakioka Magnetic Observatory in Ibaraki prefecture during the period from November, 1976 to June, 1977 (Fig. 2(a)), from June, 1977 to January, 1978 (Fig. 2(b)) and from January, 1978 to March, 1978 (Fig. 2(c)), respectively. In Fig. 2, SH indicates the relay station established at Sugehiki where the total magnetic intensity has continually been observed by the Earthquake Research Institute group (SASAI and IsHIKAWA, 1977, 1978).

In this paper, Rikitake's method is extended to the case in which an anomaly is given in terms of the total intensity and actually applied to the total intensity changes associated with the Izu-Oshima Kinkai earthquake (magnitude 7.0, January 14, 1978).

\section{Theory}

Let us take a Catesian coordinate system $(x, y, z)$ as illustrated in Fig. 3 and consider a sphere which is magnetized uniformly. The simultaneous equations for Gauss coefficients of the potential of magnetic anomaly field as obtained by RIKITAKE (1950a, b) are expressed by the following Eqs. (1), (2), and (3). In this paper we use the same notations as used in Rikitake's paper, but the coordinate system is somewhat different. 

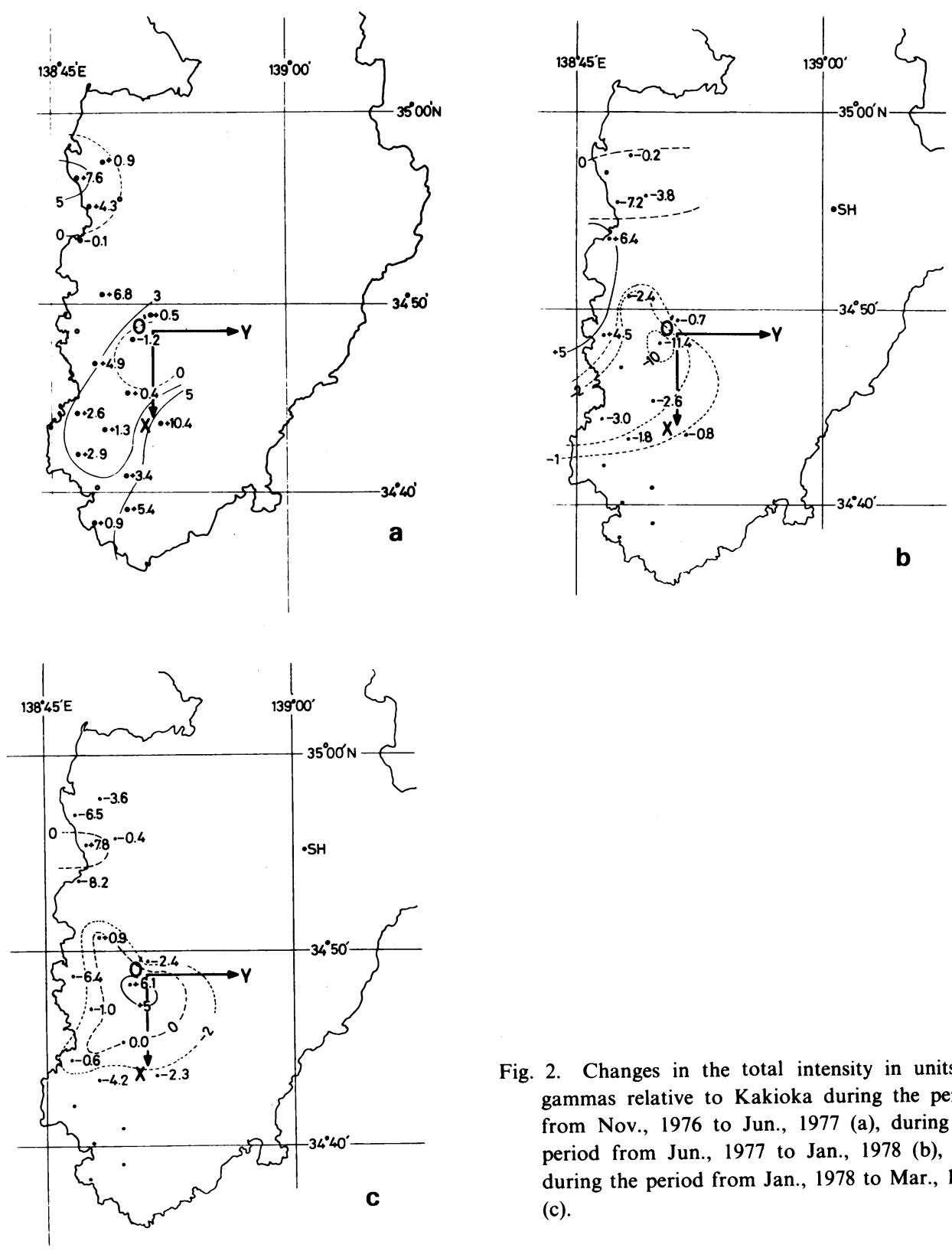

Fig. 2. Changes in the total intensity in units of gammas relative to Kakioka during the period from Nov., 1976 to Jun., 1977 (a), during the period from Jun., 1977 to Jan., 1978 (b), and during the period from Jan., 1978 to Mar., 1978 (c).

$$
\begin{gathered}
a_{1}^{1}+\sqrt{3} a_{2}^{1}=X_{00} \\
3 a_{1}^{0}+6 a_{2}^{0}-\sqrt{3} a_{2}^{2}=a \frac{\partial X_{00}}{\partial x}
\end{gathered} \mid
$$



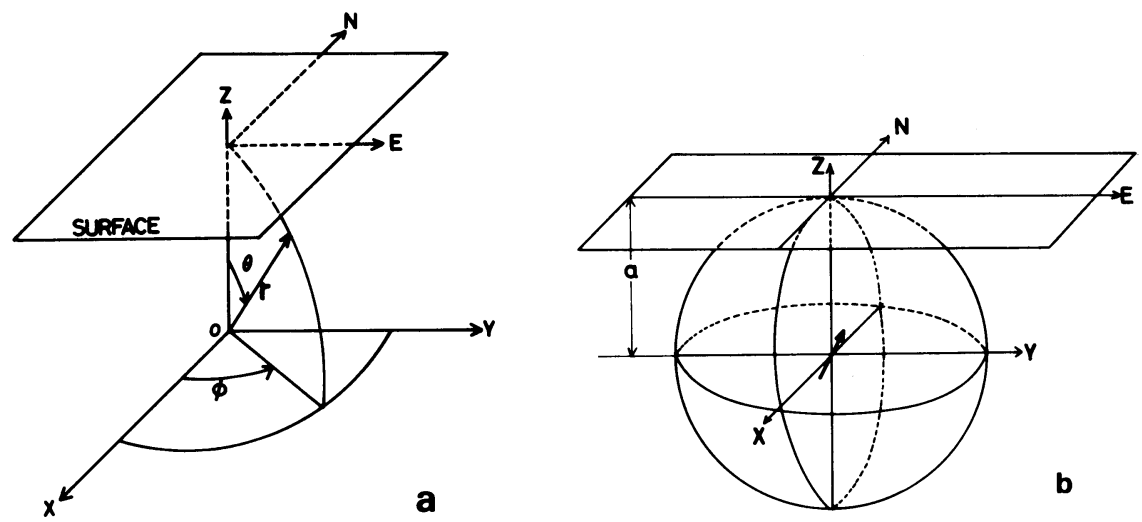

Fig. 3. $(x, y, z)$ coordinate system and $(r, \theta, \phi)$ coordinate system (a). An underground sphere that contains all of the magnetized matter. The depth and radius of the center are $a$ (b).

$$
\left.\begin{array}{rl}
-\sqrt{3} b_{2}^{2} & =a \frac{\partial X_{00}}{\partial y} \\
-9 a_{1}^{1}-15 \sqrt{3} a_{2}^{1} & =a^{2} \frac{\partial^{2} X_{00}}{\partial x^{2}} \\
-3 b_{1}^{1}-5 \sqrt{3} b_{2}^{1} & =a^{2} \frac{\partial^{2} X_{00}}{\partial x \partial y} \\
-3 a_{1}^{1}-5 \sqrt{3} a_{2}^{1} & =a^{2} \frac{\partial^{2} X_{00}}{\partial y^{2}} \\
-45 a_{1}^{0}-135 a_{2}^{0}+30 \sqrt{3} a_{2}^{2} & =a^{3} \frac{\partial^{3} X_{00}}{\partial x^{3}} \\
15 \sqrt{3} b_{2}^{2} & =a^{3} \frac{\partial^{3} X_{00}}{\partial x^{2} \partial y} \\
-15 a_{1}^{0}-45 a_{2}^{0} & =a^{3} \frac{\partial^{3} X_{00}}{\partial x \partial y^{2}} \\
15 \sqrt{3} b_{2}^{2} & =a^{3} \frac{\partial^{3} X_{00}}{\partial y^{3}}
\end{array}\right\}
$$




$$
\left.\begin{array}{rl}
-3 b_{1}^{1}-5 \sqrt{3} b_{2}^{1} & =a^{2} \frac{\partial^{2} Y_{00}}{\partial x^{2}} \\
-3 a_{1}^{1}-5 \sqrt{3} a_{2}^{1} & =a^{2} \frac{\partial^{2} Y_{00}}{\partial x \partial y} \\
-9 b_{1}^{1}-15 \sqrt{3} b_{2}^{1} & =a^{2} \frac{\partial^{2} Y_{00}}{\partial y^{2}} \\
15 \sqrt{3} b_{2}^{2} & =a^{3} \frac{\partial^{3} Y_{00}}{\partial x^{3}} \\
-15 a_{1}^{0}-45 a_{2}^{0} & =a^{3} \frac{\partial^{3} Y_{00}}{\partial x^{2} \partial y} \\
15 \sqrt{3} b_{2}^{2} & =a^{3} \frac{\partial^{3} Y_{00}}{\partial x \partial y^{2}} \\
45 b_{1}^{1}+90 \sqrt{3} b_{2}^{1} & =a^{3} \frac{\partial^{3} Z_{00}}{\partial y^{3}} \\
15 a_{1}^{1}+30 \sqrt{3} a_{2}^{1} & =a^{3} \frac{\partial^{3} Z_{00}}{\partial x \partial y^{2}} \\
5 \sqrt{3} b_{2}^{2} & =a^{2} \frac{\partial^{2} Z_{00}}{\partial x \partial y} \\
135 a_{2}^{0}-30 \sqrt{3} a_{2}^{2} & =a^{3} \frac{\partial^{3} Y_{00}}{\partial y^{3}}
\end{array}\right\}
$$


In the above equations, $a_{n}^{m}$ and $b_{n}^{m}(n=1,2 ; m=0,1,2)$ are Gauss coefficients of the magnetic anomaly potential due to the magnetized matter. $a$ is the radius of the sphere, while $X_{00}, Y_{00}, Z_{00}, \partial X_{00} / \partial x, \partial Y_{00} / \partial x, \partial Z_{00} / \partial x$, etc. are given from Taylor expansions of $X$ (south component of horizontal intensity), $Y$ (east component of horizontal intensity), and $Z$ (vertical intensity) with respect to the point $(0,0, a)$ on the plane expressed by $z=a$.

If the anomalous values of the total intensity and each component are sufficiently smaller than those of the main field, the following relation should hold

$$
\Delta F=\frac{\Delta X \cdot X_{n}+\Delta Y \cdot Y_{n}+\Delta Z \cdot Z_{n}}{F_{n}}
$$

where $X_{n}, Y_{n}$, and $Z_{n}$ denote respectively the southward, eastward and upward components of the normal magnetic field (see Fig. 3), while $F_{n}$ denotes the normal value of the total intensity. $\Delta X, \Delta Y, \Delta Z$, and $\Delta F$ denote their anomalies. In an area of local extent, $X_{n}, Y_{n}$, and $Z_{n}$ can be treated to be constant. Then, the following relations are derived from Eqs. (1) to (4).

$$
\begin{aligned}
& \frac{X_{n}}{F_{n}}\left(a_{1}^{1}+\sqrt{3} a_{2}^{1}\right)+\frac{Y_{n}}{F_{n}}\left(b_{1}^{1}+\sqrt{3} b_{2}^{1}\right)+\frac{Z_{n}}{F_{n}}\left(2 a_{1}^{0}+3 a_{2}^{0}\right)=F_{00} \\
& \frac{X_{n}}{F_{n}}\left(3 a_{1}^{0}+6 a_{2}^{0}-\sqrt{3} a_{2}^{2}\right)+\frac{Y_{n}}{F_{n}}\left(-\sqrt{3} b_{2}^{2}\right)-\frac{Z_{n}}{F_{n}}\left(3 a_{1}^{1}+4 \sqrt{3} a_{2}^{1}\right)=a \frac{\partial F_{00}}{\partial x} \\
& \frac{X_{n}}{F_{n}}\left(-\sqrt{3} b_{2}^{2}\right)+\frac{Y_{n}}{F_{n}}\left(3 a_{1}^{0}+6 a_{2}^{0}+\sqrt{3} a_{2}^{2}\right)-\frac{Z_{n}}{F_{n}}\left(3 b_{1}^{1}+4 \sqrt{3} b_{2}^{1}\right)=a \frac{\partial F_{00}}{\partial y} \\
& \frac{X_{n}}{F_{n}}\left(-9 a_{1}^{1}-15 \sqrt{3} a_{2}^{1}\right)+\frac{Y_{n}}{F_{n}}\left(-3 b_{1}^{1}-5 \sqrt{3} b_{2}^{1}\right) \\
& -\frac{Z_{n}}{F_{n}}\left(12 a_{1}^{0}+30 a_{2}^{0}-5 \sqrt{3} a_{2}^{2}\right)=a^{2} \frac{\partial^{2} F_{00}}{\partial x^{2}} \\
& \frac{X_{n}}{F_{n}}\left(-3 b_{1}^{1}-5 \sqrt{3} b_{2}^{1}\right)+\frac{Y_{n}}{F_{n}}\left(-3 a_{1}^{1}-5 \sqrt{3} a_{2}^{1}\right)+\frac{Z_{n}}{F_{n}}\left(5 \sqrt{3} b_{2}^{2}\right)=a^{2} \frac{\partial^{2} F_{00}}{\partial x \partial y} \\
& \frac{X_{n}}{F_{n}}\left(-3 a_{1}^{1}-5 \sqrt{3} a_{2}^{1}\right)+\frac{Y_{n}}{F_{n}}\left(-9 b_{1}^{1}-15 \sqrt{3} b_{2}^{1}\right) \\
& -\frac{Z_{n}}{F_{n}}\left(12 a_{1}^{0}+30 a_{2}^{0}+5 \sqrt{3} a_{2}^{2}\right)=a^{2} \frac{\partial^{2} F_{00}}{\partial y^{2}} \\
& \frac{X_{n}}{F_{n}}\left(-45 a_{1}^{0}-135 a_{2}^{0}+30 \sqrt{3} a_{2}^{2}\right)+\frac{Y_{n}}{F_{n}}\left(15 \sqrt{3} b_{2}^{2}\right) \\
& +\frac{Z_{n}}{F_{n}}\left(45 a_{1}^{1}+90 \sqrt{3} a_{2}^{1}\right)=a^{3} \frac{\partial^{3} F_{00}}{\partial x^{3}} \\
& \frac{X_{n}}{F_{n}}\left(15 \sqrt{3} b_{2}^{2}\right)+\frac{Y_{n}}{F_{n}}\left(-15 a_{1}^{0}-45 a_{2}^{0}\right)+\frac{Z_{n}}{F_{n}}\left(15 b_{1}^{1}+30 \sqrt{3} b_{2}^{1}\right)=a^{3} \frac{\partial^{3} F_{00}}{\partial x^{2} \partial y} \\
& \frac{X_{n}}{F_{n}}\left(-15 a_{1}^{0}-45 a_{2}^{0}\right)+\frac{Y_{n}}{F_{n}}\left(15 \sqrt{3} b_{2}^{2}\right)+\frac{Z_{n}}{F_{n}}\left(15 a_{1}^{1}+30 \sqrt{3} a_{2}^{1}\right)=a^{3} \frac{\partial^{3} F_{00}}{\partial x \partial y^{2}}
\end{aligned}
$$




$$
\begin{aligned}
\frac{X_{n}}{F_{n}}\left(15 \sqrt{3} b_{2}^{2}\right) & +\frac{Y_{n}}{F_{n}}\left(-45 a_{1}^{0}-135 a_{2}^{0}-30 \sqrt{3} a_{2}^{2}\right) \\
& +\frac{Z_{n}}{F_{n}}\left(45 b_{1}^{1}+90 \sqrt{3} b_{2}^{1}\right)=a^{3} \frac{\partial^{3} F_{00}}{\partial y^{3}}
\end{aligned}
$$

$$
\int
$$

If the pattern, on the $x y$-plane, of the magnetic anomaly in the total magnetic intensity is expressed in the form

$$
F=A+B x+C y+D x^{2}+E x y+F y^{2}+G x^{3}+H x^{2} y+I x y^{2}+J y^{3}
$$

then $F_{00}, \partial F_{00} / \partial x, \partial F_{00} / \partial y$, etc. are calculated from the constants $A$ to $J$. The Gauss coefficients $a_{1}^{0}, a_{1}^{1}, b_{1}^{1}$, etc. are then determined as the solution of these simultaneous equations. It should be borne in mind, however, that the radius (or the depth of the dipole) $a$ remains unknown. $a$ can be determined, for example, under the condition that the square sum of Gauss coefficients of degree 2 should be minimized. This means that we attempt to approximate the actual field by an eccentric dipole as closely as we can. Such a condition is written as

$$
\left(a_{2}^{0}\right)^{2}+\left(a_{2}^{1}\right)^{2}+\left(b_{2}^{1}\right)^{2}+\left(a_{2}^{2}\right)^{2}+\left(b_{2}^{2}\right)^{2}=\text { minimum }
$$

or

$$
\left\{\left(a_{2}^{0}\right)^{2}+\left(a_{2}^{1}\right)^{2}+\left(b_{2}^{1}\right)^{2}+\left(a_{2}^{2}\right)^{2}+\left(b_{2}^{2}\right)^{2}\right\} /\left\{\left(a_{1}^{0}\right)^{2}+\left(a_{1}^{1}\right)^{2}+\left(b_{1}^{1}\right)^{2}\right\}=\text { minimum . }
$$

In other words, we must find out the value of $a$ which satisfies the condition (7) or (8) by means of trial and error. If $a$ is obtained, the position of the magnetic dipole can be determined by the following relations (SCHMIDT, 1943).

$$
\left.\begin{array}{c}
x_{0}=a\left(L_{1}-a_{1}^{1} E\right) / 3 H_{0}^{2} \\
y_{0}=a\left(L_{2}-b_{1}^{1} E\right) / 3 H_{0}^{2} \\
z_{0}=a\left(L_{0}-a_{1}^{0} E\right) / 3 H_{0}^{2}
\end{array}\right\}
$$

where

$$
\begin{aligned}
H_{0}^{2} & =a_{1}^{0} a_{1}^{0}+a_{1}^{1} a_{1}^{1}+b_{1}^{1} b_{1}^{1} \\
L_{0} & =2 a_{1}^{0} a_{2}^{0}+\left(a_{1}^{1} a_{2}^{1}+b_{1}^{1} b_{2}^{1}\right) \sqrt{3} \\
L_{1} & =-a_{1}^{1} a_{2}^{0}+\left(a_{1}^{0} a_{2}^{1}+a_{1}^{1} a_{2}^{2}+b_{1}^{1} b_{2}^{2}\right) \sqrt{3} \\
L_{2} & =-b_{1}^{1} a_{2}^{0}+\left(a_{1}^{0} b_{2}^{1}-b_{1}^{1} a_{2}^{2}+a_{1}^{1} b_{2}^{2}\right) \sqrt{3} \\
E & =\left(L_{0} a_{1}^{0}+L_{1} a_{1}^{1}+L_{2} b_{1}^{1}\right) / 4 H_{0}^{2} .
\end{aligned}
$$

Finally the depth of the magnetic dipole is determined by using the radius of the sphere and the Eq. (9), and the direction of the magnetic dipole is derived from the coefficients. Dipole determination based on the method mentioned above, however, depends upon the location of the origin of the coordinate system. Therefore, we should take the origin of the coordinate system by taking into consideration the physical 
meaning of an underground magnetic dipole.

\section{Local Changes in the Total Intensity}

The proton precession magnetometers with an acuracy of $\pm 1 \gamma$ were used for the surveys and the error due to their instrumental deviation was within the accuracy whenever it was checked. Magnetic stations were set up in places where the local horizontal and vertical field gradients were less than $10 \gamma / \mathrm{m}$. The magnetic surveys were carried out during the nighttime in November, 1976 and June, 1977, because data at the relay station, Sugehiki, were not available during the above surveys. The other surveys were carried out during the daytime. At each station the total intensity was measured every minute for $20 \mathrm{~min}$ except for the surveys in November, 1976, June, 1977, and January, 1978. During these surveys measurments were made only for $15 \mathrm{~min}$. The difference in the total intensity between the relay and reference stations was obtained by making use of nighttime data of one-hour duration at a magnetically quiet time.

Loal magnetic changes in total intensity accompanying the Izu-Oshima Kinkai
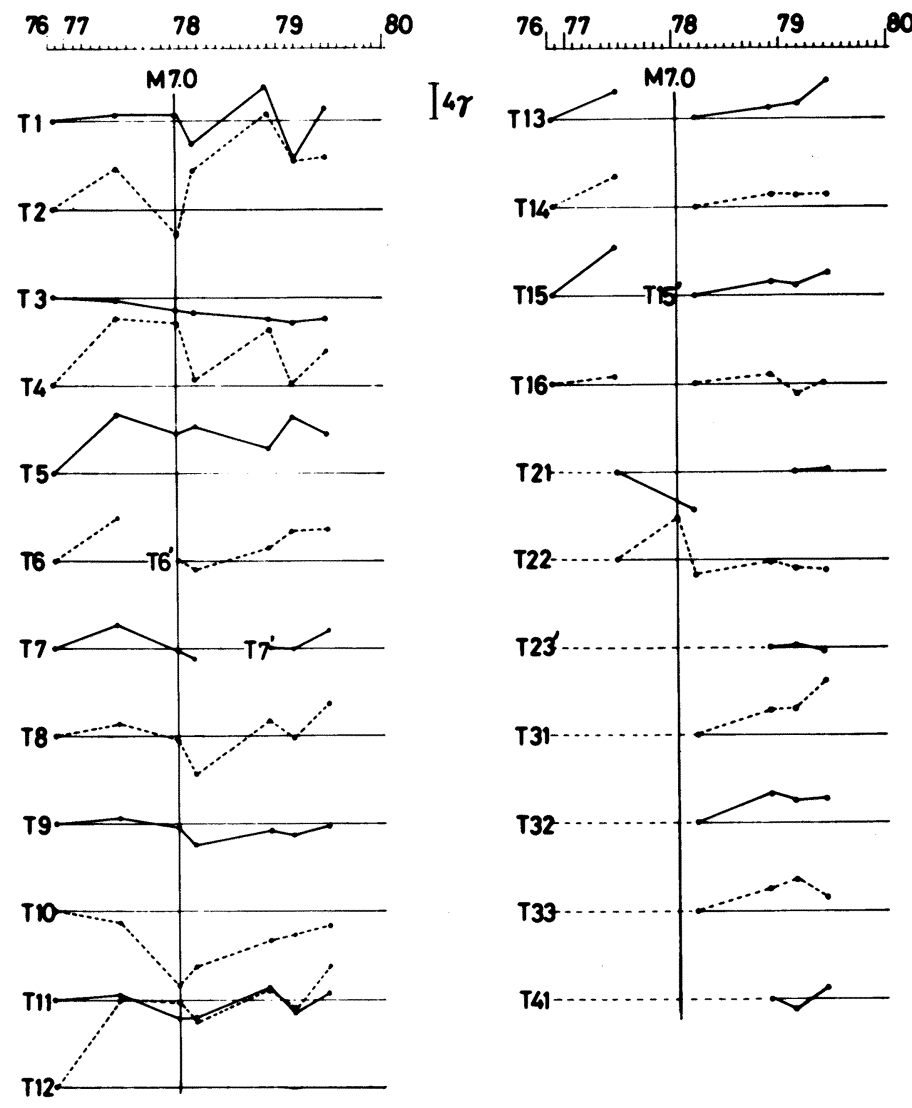

Fig. 4. Secular changes in the toral intensity relative to Kakioka at each magnetic station. 
earthquake is already shown in Fig. 2. It is clearly seen in the figures that the changes in the total intensity as shown in Figs. 2(b) and (c) are almost opposite in their sign to one another. Since the magnetic survey was carried out only twice before the earthquake, a detailed examination of changes in the total intensity is not possible. However, the tendency of changes after the earthquake can be examined from Figs. 4 and 5. Figure 5 illustrates the contoured map of total intensity changes during the period from March, 1978 to June, 1979. Secular changes in the total intensity at each station during the whole survey period are shown in Fig. 4.

As is evident from these figures, the local magnetic field tends to increase in the southern part of Izu Peninsula; up to $6 \gamma$ during the period from March, 1978 to June, 1979. The rate of increase varies little from one station to another (see Fig. 4). On the other hand, in the central part of the survey area slight negative changes appeared during the same period. At survey stations in the northern part, farily large changes were observed not only during the period including the earthquake occurrence but also after the earthquake, although the average trend is a small increase, about $2 \gamma$ during the above period, as is shown in Fig. 5.

Figure 6 illustrates the epicenter of the Izu-Oshima Kinkai earthquake and the distribution of its aftershocks (TSUMURA et al. 1978), and also illustrates a fault, F4, determined by OKADA (1978). This fault is a left-lateral stike-slip fault, and its parameters are listed in Table 1. The amount of displacement for the fault F4 was determined by the author, using the following equations (OHNAKA, 1975) on the assumption that the largest aftershock $(M=5.8)$ which occurred in the western part of Izu Peninsula was associated with the fault F4.

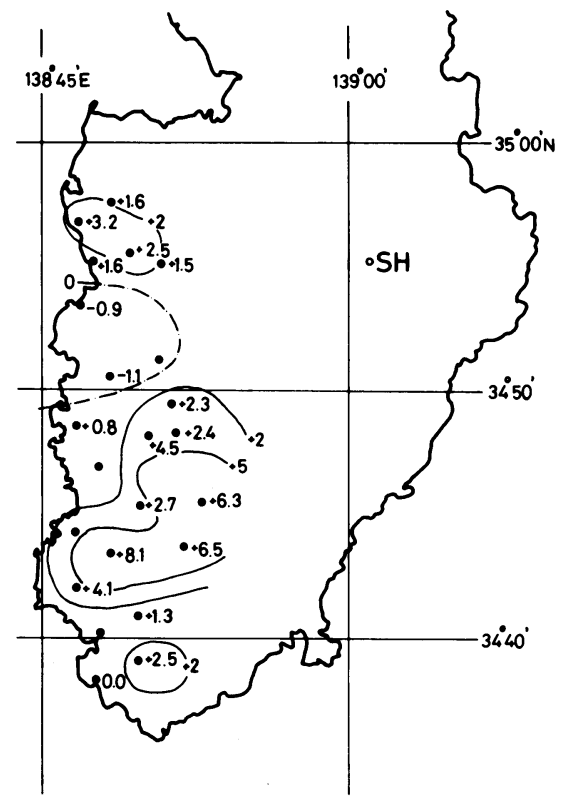

Fig. 5. Contoured map of changes in the total intensity in units of gammas relative to Kakioka during the period from Mar., 1978 to Jun., 1979. 


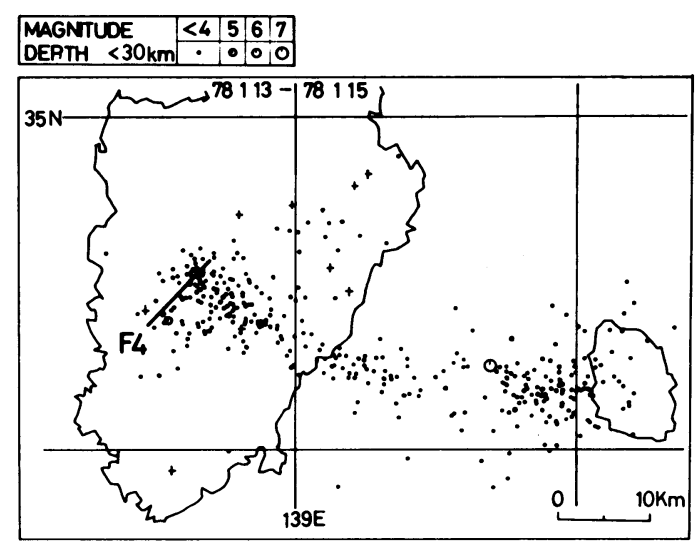

Fig. 6. Epicentral distribution of the foreshocks, mainshock and aftershocks during the period from Jan. 13 to 15, 1978 (after TsumURA et al., 1978). F4 indicates the left lateral strike slip fault (after OKADA, 1978).

Table 1. Parameters of the fault F4 (after OKADA, 1978).

$\begin{array}{lc}\text { Fault strike } & \mathrm{N} 40^{\circ} \mathrm{E} \\ \text { Dip angle } & 90^{\circ} \\ \text { Slip angle } & 0^{\circ} \\ \text { Fault length } & 10 \mathrm{~km} \\ \text { Fault width } & 7.5 \mathrm{~km} \\ \text { Fault depth } & 10 \mathrm{~km} \\ \text { Dislocation: left lateral strike slip } & 19 \mathrm{~cm}\end{array}$

The amount of displacement for fault F4 was determined by using the equations, $\log \left(M_{0} / L\right)=1.2 M+11.7$ and $M_{0}=\mu U_{0} S$, on the assumption that the largest aftershock $(M=5.8)$ which occurred with the fault F4 since it has not been well determined in Okada's paper.

$$
\begin{aligned}
\log \left(\frac{M_{0}}{L}\right) & =1.2 M+11.7 \\
M_{0} & =\mu U_{0} S
\end{aligned}
$$

where $U_{0}, M_{0}, M, S, L$, and $\mu\left(=3.5 \times 10^{11}\right)$ are the displacement, the seismic moment, the magnitude, the area of the fault, the fault length and the shear modulus, respectively.

According to STACEY (1964), vectors for magnetization changes caused by the shear stress release accompanying a strike-slip of a vertical fault lying in a direction of $\mathrm{N} 40^{\circ} \mathrm{E}$ like the fault F4 point to the north on a horizontal plane. Therefore, in order to investigate the origin of the negative anomaly in Fig. 2(b), which seems to be caused by the fault $\mathrm{F} 4$, the origin $\mathrm{O}^{\prime}$ of the plane Cartesian coordinate system $(x, y)$ was taken at the center of the fault F4 as is shown in Fig. 2. Then, the origin $\mathrm{O}$ of the Catesian coordinate system $(x, y, z)$ is located beneath $\mathrm{O}^{\prime}$. (The depth of the origin from the earth's surface can be determined by solving the simultaneous Eqs. (5).) The results of analyses are summarized in Table 2 . In the analyses, we assumed typical values of field intensity in this 
Table 2. The undergound magnetic dipole moments corresponding to changes of the total intensity during each period.

\begin{tabular}{|c|c|c|c|c|c|c|}
\hline \multirow{2}{*}{\multicolumn{2}{|c|}{ Period }} & \multirow{2}{*}{$\begin{array}{c}\text { Moment } \\
\text { (emu) }\end{array}$} & \multicolumn{2}{|c|}{ Direction } & \multirow{2}{*}{$\begin{array}{l}\text { Depth } \\
(\mathrm{km})\end{array}$} & \multirow{2}{*}{$\begin{array}{c}\Delta J_{n} \\
(\mathrm{emu} / \mathrm{cc})\end{array}$} \\
\hline & & & $\theta$ & $\phi$ & & \\
\hline Nov. 1976 & Jun. 1977 & $1.90 \times 10^{13}$ & -68.4 & -76.3 & 7.9 & $9.20 \times 10^{-6}$ \\
\hline Jun. 1977 & Jan. 1978 & $5.50 \times 10^{12}$ & 28.8 & 86.2 & 5.4 & $8.34 \times 10^{-6}$ \\
\hline Jan. 1978 & Mar. 1978 & $4.21 \times 10^{11}$ & -73.9 & -73.9 & 3.3 & $2.80 \times 10^{-6}$ \\
\hline
\end{tabular}

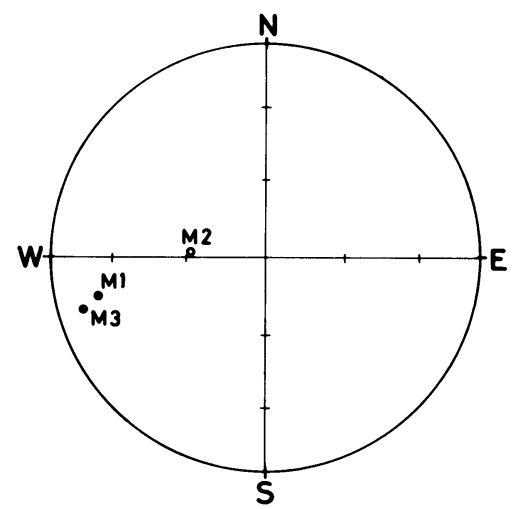

Fig. 7. The equal-area projection of the underground magnetic dipole. M1, M2, and M3 denote the dipoles during the period from Nov., 1976 to Jun., 1977, from Jun., 1977 to Jan., 1978, and from Jan., 1978 to Mar., 1978, respectively.

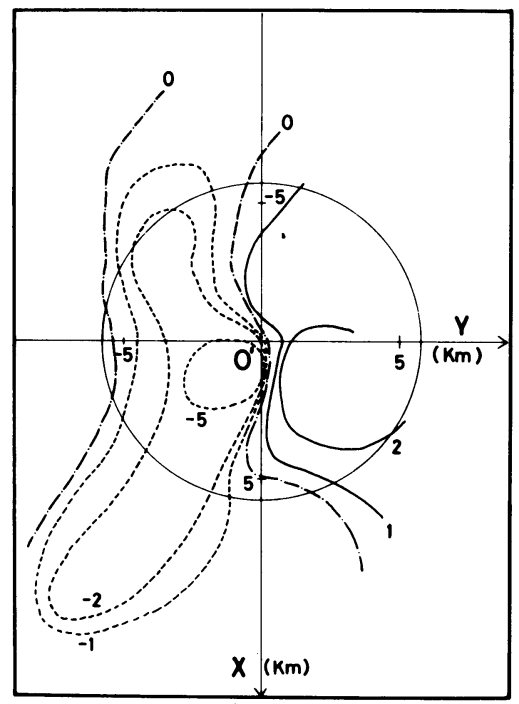

Fig. 8. Contoured map of differences between calculated changes and observed changes in units of gammas. 
portion of Japan, say $0.46 \Gamma,-0.30 \Gamma,-0.03 \Gamma$, and $-0.34 \Gamma$, for $F_{n}, X_{n}, Y_{n}$, and $Z_{n}$, respectively. Depths of magnetic dipoles during the periods from November, 1976 to June, 1977 and from January, 1978 to March, 1978 were determined by using the conditions (8). The direction of the magnetic dipole determined is slightly downward during the period from November, 1976 to June, 1977, roughly upward during the period from June, 1977 to January, 1978, and slightly downward from January, 1978 to March, 1978, as illustrated in Fig. 7 by means of the equal-area projection. Figure 8 illustrates the contoured map of difference between changes calculated from the underground dipole and changes observed during the period June, 1977 to January, 1978. It is clearly seen from this figure that discrepancy is rather large near the origin $\mathrm{O}^{\prime}$.

\section{Tectonomagnetic Interpretation}

As mentioned above, a magnetic dipole, which has no $Z$-component, caused by the movement of the fault F4 points to the north, according to Stacey's model. However, the magnetic dipole M2 does not point to the north but rather to the east as is clearly seen in Fig. 7. Moreover, non-zero Z-component appears. A few reasons for this discrepancy can be considered. 1) The magnetic dipole M2 may be insignificant because of large errors. 2) The observed changes in the total magnetic intensity may not be due to the displacement of the fault F4. 3) Stacey's model itself may not represent actual geomagnetic changes well.

Although we cannot quite deny the first and third possibilities, we should take the second reason as a likely one because the displacement of the fault F4 seems to be too small $(U=19 \mathrm{~cm})$ to produce large geomagnetic changes on the earth's surface. Since the stress drop accompanying the displacement of the fault F4 is estimated as 5.6 bars, the observed changes in the total intensity cannot be explained from Stacey's model if we assume that the average intensity of magnetization of the earth's crust is $5 \times 10^{-3}$ $\mathrm{emu} / \mathrm{cm}^{3}$. Therefore, it seems reasonable to presume that most portions of the geomagnetic changes observed in the western part of Izu Peninsula are caused by the displacement of the main fault (SHIMAZAKI and SomER VILLE, 1978) or by that of the sub-

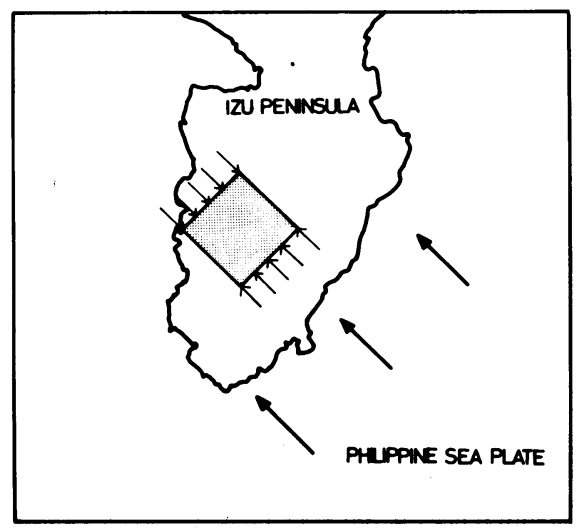

Fig. 9. Tectonic model of Izu Peninsula. 
fault in the eastern part of Izu Peninsula (OKADA, 1978).

On the other hand, an interpretation based on a rather simple model might be possible for the magnetic dipoles during the periods from November, 1976 to June, 1977 and from January, 1978 to March, 1978. Let us assume that Izu Peninsula is compressed by Phillippine Sea Plate, which is moving north-westward as widely accepted in the plate tectonics. Figure 9 illustrates a model; the square area is assumed to be under a uniaxial compression in the illustrated direction. If the natural remanent magnetization (NRM) of ignerous rocks in Izu Peninsula is assumed to be directed toward the north with a dip angle of $45^{\circ}$ or thereabout, the direction of NRM should de deflected downward by the compression, because the component of NRM parallel to the direction of the compression decreases, whereas the perpendicular one increases. In this case, the thermoremanent magnetization (TRM) is considered as th major portion of NRM. It is expected, therefore, that a magnetic dipole having a downward component appears when the compression is predominant.

\section{Concluding Remarks}

The geomagnetic changes observed at survey stations in the western part of Izu Peninsula, except in the northern one, during the period from June, 1977 to January, 1978 are considered to be co-seismic ones accompanying the Izu-Oshima Kinkai earthquake. Such a presumption seems reasonable since the secular changes after the earthquake are characterized by a similar trend at any station except ones in the northern part (see Fig. 4).

However, it seems unreasonable to interpret these changes in terms of seismic activities, particularly the largest aftershock $(M=5.8)$, in the western part of Izu Peninsula after the main shock, as implied by the unsuccessful result of underground magnetic dipole model by which an attempt was made to account for changes during the period from June, 1977 to January, 1978. The displacement of the sub-fault in the eastern part of Izu Peninsula as well as that of the main fault should be taken into account in order to obtain a reasonable interpretation for the geomagnetic changes observed in the western part of Izu Peninsula.

The author would like to thank Professor T. Rikitake for his guidance in this study. The author is also thankful to Associate Professor Y. Honkura for critically reading the manuscript.

The author wishes to express his sincere thanks to Mr. S. Koyama of the Earthwquake Research Institute and also to Mr. H. Tanaka, who helped him carry out the magnetic surveys and gave him some useful advice. To Mr. Y. Sasai of the Earthquake Research Institute and Mr. K. Ohchi of the Kakioka Magnetic Observatory who placed magnetic data at the author's request, the author's cordial thanks are also due.

\section{REFERENCES}

Davis, P. M., The computed piezomagnetic anomaly field for Kilauea Volcano, Hawaii, J. Geomag. Geoelectr., 28, 113-122, 1976.

FujITA, N., The magnetic disturbances accompanying the Niigata earthquake, J. Geod. Soc. Japan, 11, 8-25, 1965 (in Japanese).

Nagata, T., Tectonomagnetism IAGA Bull., 27, 12-43, 1969.

OHNAKA, M., A physical basis for earthquakes based on the elastic rebound model, Bull. Earthq. Res. Inst., Univ. Tokyo, 50, 187-208, 1975 (in Japanese). 
OKADA, Y., Fault mechanism of the Izu-Oshima-Kinkai earthquake of 1978, as inferred from the crustal movement data, Bull. Earthq. Res. Inst., Univ. Tokyo, 53, 823-840, 1978 (in Japanese).

RikitaKE, T., Magnetic anomalies and the corresponding magnetic centre I., J. Geomag. Geoelectr., 2, 20-24, 1950a.

RIKITAKE, T., Magnetic anomalies and the corresponding magnetic centre II, J. Geomag. Geoelectr., 2, 25-28, $1950 \mathrm{~b}$.

RIKITAKE, T., The distribution of magnetic dip in Ooshima (Oo-shima) Island and its change that accompanied the eruption of Volcano Mihara 1950, Bull. Earthq. Res. Inst., Univ. Tokyo, 29, 161-181, 1951.

SASAI, Y., The piezomagnetic field associated with the Mogi model, Bull. Earthq. Res. Inst., Univ. Tokyo, 54, $1-29,1979$.

SASAI, Y. and Y. ISHIKAWA, Changes in the geomagnetic total force intensity associated with the anomalous crustal activity in the eastern part of the Izu Peninsula (1), Bull. Earthq. Res. Inst., Univ. Tokyo, 52, 173-190, 1977 (in Japanese).

SASAI, Y. and Y. IshIKAWA, Changes in the geomagnetic total force intensity associated with the anomalous crustal activity in the eastern part of the Izu Peninsula (2) - the Izu-Oshima-Kinkai earthquake of 1978-, Bull. Earthq. Res. Inst., Univ. Tokyo, 53, 893-923, 1978 (in Japanese).

SchmidT, A., Der magnetische Mittelpunkt der Erde und seine Bedeutung, Gerlands Beitr. Geophys., 41, 346-358, 1943.

ShimaZaKi, K. and P. Somerville, Summary of the static and dynamic parameters of the Izu-Oshima-Kinkai earthquake of January 14, 1978, Bull. Earthq. Res. Inst., Univ. Tokyo, 53, 613-628, 1978.

Stacey, F. D., The seismomagnetic effect, Pure Appl. Geophys., 58, 5-22, 1964.

TANAKA, H. and N. OHShiman, Changes in the geomagnetic total force observed in the western part of the Izu Peninsula associated with the 1978 near-Izu-Oshima Island earthquake, Rep. Coord. Comm. Earthq. Predict., 20, 77-80, 1978 (in Japanese).

Tsumura, K., I. Karakama, I. Ogino, and M. Takahashi, Seismic activities before and after the Izu-OshimaKinkai earthquake of 1978, Bull Earthq. Res. Inst., Univ. Tokyo, 53, 675-706, 1978 (in Japanese).

YUKUTAKE, T. and H. TACHINAKA, Geomagnetic variation associated with stress change within a semi-infinite elastic earth caused by a cylindrical force source, Bull. Earthq. Res. Inst., Univ. Tokyo, 45, 785-798, 1967. 